\title{
The Impact of the COVID-19 Pandemic on Breast Cancer Patients
}

\author{
(D) Ahmet Serkan İlgün ${ }^{1}$, (D) Vahit Özmen² \\ ${ }^{1}$ Department of General Surgery, Demiroğlu Science University School of Medicine, İstanbul, Turkey \\ ${ }^{2}$ Prof of Surgery, İstanbul Florence Nightingale Hospital, Breast Health Centre, İstanbul, Turkey
}

\section{ABSTRACT}

Objective: The coronavirus disease-2019 (COVID-19) pandemic causes delays in the diagnosis and treatment of cancer patients due to fear of contagion and lockdown. This study aims to investigate the effects of the COVID-19 pandemic on breast cancer patients treated in our breast center.

Materials and Methods: Patients who applied to our clinic with the diagnosis of invasive breast cancer in March 2020 and March 2021 (Study Group) when the COVID-19 pandemic was observed, and in March 2019 and March 2020 before the COVID-19 pandemic (Control Group) were compared in terms of demographic, clinical and pathological characteristics. Statistical analyses were performed using the SPSS software version 21.

Results: There were $176(46 \%)$ patients in the study and 206 (54\%) patients in the control group. Almost a 15\% reduction was detected in patients admitted during the COVID-19 pandemic. The rate of pre-menopausal patients and patient-related delay time (PRDT) were significantly higher in SG $(57.7 \%$ vs. $\% 45, \mathrm{p}=0.013,2.58$ vs. 1.82 -month, $\mathrm{p}=0.001$, respectively). There was a larger tumor size and more metastatic lymph nodes after NAC in the SG, but the differences were not significant. There was no difference regarding breast cancer stages and molecular subtypes between the two groups, but there was significantly more de novo stage IV breast cancer in the SG $(\mathrm{p}=0.009)$. The incidence of neo-adjuvant chemotherapy and type of surgical therapy was similar between the two groups.
\end{abstract}

Conclusion: COVID-19 pandemic caused a decrease in the number of patients who applied to our clinic and increased patient-related delay time due to fear of transmission and lockdown. The rate of de novo stage IV breast cancer was also significantly increased.

Keywords: Breast cancer, COVID-19, de novo breast cancer, metastatic cancer, pandemic, patient-related delay time

Cite this article as: İlgün AS, Özmen V. The Impact of the COVID-19 Pandemic on Breast Cancer Patients. Eur J Breast Health 2022; 18(1): 85-90

\section{Key Points}

- Patient-related delay time increased during the COVID-19 pandemic.

- Frequency of de nevo metastatic breast cancer increased during the COVID-19 pandemic.

- Breast conservation rate did not change during the COVID-19 pandemic.

\section{Introduction}

Coronavirus disease-2019 (COVID-19) pandemic started as a cluster of cases with pneumonia reported by the Wuhan Municipal Health Commission on December 31, 2019. On March 11, 2020, WHO (World Health Organization) assessed that COVID-19 can be characterized as a pandemic (1). The first COVID -19 case in Turkey was reported on March 11, 2020 (2). With the increase in COVID-19 cases, elective and non-urgent surgical procedures, including cancer, have been delayed in hospitals all over Turkey as in the whole world $(3,4)$.

Along with the lockdowns, patients started to refrain from applying to hospitals. According to a report from Finland (5), the most common operation, laparoscopic appendicectomy, decreased by 32\% three weeks before the lockdown in March 2020. According to the same report, hospital admissions decreased (5).

Care of breast cancer patients affected by COVID-19 pandemic. Breast surgery delayed for early breast cancer patients if they had hormone receptor-positive cancers. Those patients were managed by endocrine treatment until appropriate conditions were established. At the beginning of May 2020, lockdown and restrictions eased. Patients with breast lumps or biopsy-proven breast cancer started to come to hospitals, and breast surgery started with precautions. 
In a study from Turkey, the total delay time in breast cancer treatment was almost 14 weeks (6). Thus, nearly one-third of the whole delay time was patient-related delay time. In the COVID-19 pandemic, it can be estimated easily that the patient-related delay time (PRDT) would be longer.

The study aimed to compare characteristics of breast cancer patients treated in our breast center before and after the COVID-19 pandemic.

\section{Materials and Methods}

The data required for this study was obtained from the patient records in our archive. The study group (SG) consisted of patients with invasive breast cancer treated between March 2020 and March 2021. The control group (CG) was composed of patients treated in the pre-COVID-19 period (March 2019-March 2020). Demographic, clinical, pathological, and treatment characteristics of patients were recorded. PRDT (patient-related delay time) was defined as the time between the onset of first symptoms and the first medical visit (this analysis included only patients with self-detected cancers). Systemrelated delay time (SRDT) was the time between the first medical visit and the start of therapy.

The breast cancer staging was done according to the AJCC $7^{\text {th }}$ edition of the TNM cancer staging system. The Demiroğlu Science University Ethics Committee approved the study.

\section{Statistical Analysis}

Statistical analyses were performed using the SPSS software version 21. The variables were investigated using visual (histograms, probability plots) and analytical methods (Kolmogorov-Smirnov test) to determine whether or not they are normally disturbed. Mann-Whitney $U$ test was used to evaluate parameters not normally disturbed, such as age and PRDT. The chi-square test was used to compare categorical parameters such as menopausal status, complaint, clinical-stage, pathologic stage, surgical treatment, molecular subtypes, and neoadjuvant treatment. A p-value of less than 0.05 was considered to show a statistically significant result.

\section{Results}

There were $176(46 \%)$ patients in the SG and 206 (54\%) patients in the CG (Table 1). Almost 15\% reduction detected in patients admitted during the COVID-19 pandemic compared to last year. Median follow-up time was 6.4 (1-25) months for all patients. It was the median of 12.6 (1-25) months for the control group and the median of 2.5 (1-15) months for the study group $(\mathrm{p}<0.001)$ (Table 1$)$. The median age was not different between the two groups [49 (27-88) vs. 47 (27-89), $\mathrm{p}=0.09$ ], while there were significantly more premenopausal patients in the SG $(57.7 \%$ vs. $45 \%, p=0.013$, Figure 1$)$. The most common symptom was a lump for both groups (Figure 2).

The patient-related delay time (PRDT) was substantially longer in the SG $[(2.58 \pm 2.1)$ months vs. $(1.82 \pm 1.4)$ months, $\mathrm{p}=0.001]$. On the other hand, system-related delay time (SDRT) was similar between the two groups (Table 1).

Table 1. Patients characteristics

\begin{tabular}{|c|c|c|c|c|}
\hline Characteristics & Total & Control group & Study group & p-value \\
\hline Number of patients & 382 & $206(54 \%)$ & $176(46 \%)$ & \multirow{2}{*}{$0.09^{\#}$} \\
\hline Median age & $48(26-89)$ & $49(27-88)$ & $47(27-89)$ & \\
\hline \multicolumn{5}{|l|}{ Menopausal status } \\
\hline Pre-menopausal & 193 & $92(45 \%)$ & $101(57.7 \%)$ & \multirow{2}{*}{$0.013^{*}$} \\
\hline Post-menopausal & 187 & $113(55 \%)$ & $74(42.3 \%)$ & \\
\hline PRDT (months) & $2.17 \pm 1.8$ & $1.82 \pm 1.4$ & $2.58 \pm 2.1$ & $0.001^{\#}$ \\
\hline SRDT (months) & $0.39 \pm 0.9$ & $0.4 \pm 1.06$ & $0.37 \pm 0.7$ & $0.57^{\#}$ \\
\hline Follow-up time-months(median) & $6.4(1-25)$ & $12.6(1-25)$ & $2.5(1-15)$ & $<0.001^{\#}$ \\
\hline \multicolumn{5}{|l|}{ Staging method } \\
\hline \multicolumn{5}{|l|}{ Patients with NAC } \\
\hline Mammography & 119 & $66(100 \%)$ & $53(100 \%)$ & \multirow{2}{*}{$0.06^{*}$} \\
\hline Breast ultrasound & 115 & $62(94 \%)$ & $53(100 \%)$ & \\
\hline Breast MRI & 67 & $35(53 \%)$ & $32(60.4 \%)$ & $0.42 *$ \\
\hline PET CT & 113 & $61(93 \%)$ & $52(98 \%)$ & $0.15^{*}$ \\
\hline Other (PET MR, CT, Bone scintigraphy) & 6 & $5(7 \%)$ & $1(2 \%)$ & \\
\hline \multicolumn{5}{|l|}{ Patients without NAC } \\
\hline Mammography & 263 & $140(100 \%)$ & $123(100 \%)$ & \\
\hline Breast ultrasound & 252 & $135(96.5 \%)$ & $117(95.1 \%)$ & $0.59 *$ \\
\hline Breast MRI & 127 & $68(49 \%)$ & $59(48 \%)$ & $0.92 *$ \\
\hline PET CT & 91 & $42(30 \%)$ & $49(39.8 \%)$ & $0.09 *$ \\
\hline Other (PET MR, CT, Bone scintigraphy) & 5 & $3(2 \%)$ & $2(1.8 \%)$ & \\
\hline
\end{tabular}


Table 1. Continued

\begin{tabular}{|c|c|c|c|c|}
\hline Characteristics & Total & Control group & Study group & p-value \\
\hline Number of patients & 382 & $206(54 \%)$ & $176(46 \%)$ & \multirow{2}{*}{$0.09^{\#}$} \\
\hline Median age & $48(26-89)$ & $49(27-88)$ & $47(27-89)$ & \\
\hline \multicolumn{5}{|l|}{ Menopausal status } \\
\hline Pre-menopausal & 193 & $92(45 \%)$ & $101(57.7 \%)$ & \multirow{2}{*}{$0.013^{*}$} \\
\hline Post-menopausal & 187 & $113(55 \%)$ & $74(42.3 \%)$ & \\
\hline PRDT (months) & $2.17 \pm 1.8$ & $1.82 \pm 1.4$ & $2.58 \pm 2.1$ & $0.001^{\#}$ \\
\hline SRDT (months) & $0.39 \pm 0.9$ & $0.4 \pm 1.06$ & $0.37 \pm 0.7$ & $0.57^{\#}$ \\
\hline Follow-up time-months(median) & $6.4(1-25)$ & $12.6(1-25)$ & $2.5(1-15)$ & $<0.001^{\#}$ \\
\hline \multicolumn{5}{|l|}{ Staging method } \\
\hline \multicolumn{5}{|l|}{ Patients with NAC } \\
\hline Mammography & 119 & $66(100 \%)$ & $53(100 \%)$ & \\
\hline Breast ultrasound & 115 & $62(94 \%)$ & $53(100 \%)$ & $0.06^{*}$ \\
\hline Breast MRI & 67 & $35(53 \%)$ & $32(60.4 \%)$ & $0.42 *$ \\
\hline PET CT & 113 & $61(93 \%)$ & $52(98 \%)$ & \multirow[t]{2}{*}{$0.15^{*}$} \\
\hline Other (PET MR, CT, Bone scintigraphy) & 6 & $5(7 \%)$ & $1(2 \%)$ & \\
\hline \multicolumn{5}{|l|}{ Patients without NAC } \\
\hline Mammography & 263 & $140(100 \%)$ & $123(100 \%)$ & \\
\hline Breast ultrasound & 252 & 135 (96.5\%) & 117 (95.1\%) & $0.59 *$ \\
\hline Breast MRI & 127 & $68(49 \%)$ & $59(48 \%)$ & $0.92 *$ \\
\hline PET CT & 91 & $42(30 \%)$ & 49 (39.8\%) & \multirow[t]{2}{*}{$0.09 *$} \\
\hline Other (PET MR, CT, Bone scintigraphy) & 5 & $3(2 \%)$ & $2(1.8 \%)$ & \\
\hline \multicolumn{5}{|l|}{ Histologic grade } \\
\hline \multicolumn{5}{|l|}{ Patients without NAC } \\
\hline HG 1 & 22 & $13(10 \%)$ & $9(8.3 \%)$ & \multirow{3}{*}{$0.44^{*}$} \\
\hline HG 2 & 107 & $57(43.5 \%)$ & $50(46 \%)$ & \\
\hline HG 3 & 109 & $61(46 \%)$ & $48(44.4 \%)$ & \\
\hline \multicolumn{5}{|l|}{ LVI } \\
\hline No & 167 & $87(51 \%)$ & $80(61 \%)$ & \multirow{2}{*}{$0.07 *$} \\
\hline Yes & 135 & $84(49 \%)$ & $51(39 \%)$ & \\
\hline Tumor size on USG (median) & & $19(5-64)$ & $21(0-70)$ & $0.1^{\#}$ \\
\hline Metastatic lymph nodes (mean) & & $1.5 \pm 3.7$ & $1.7 \pm 2.2$ & $0.92^{\#}$ \\
\hline Patients with NAC & & $1.9 \pm 3.4$ & $2.2 \pm 3.3$ & $0.63^{\#}$ \\
\hline Patients without NAC & & $1.4 \pm 4$ & $1.09 \pm 2.6$ & $0.33^{\#}$ \\
\hline \multicolumn{5}{|l|}{ Clinical stage } \\
\hline Stage 1 & $134(38 \%)$ & $69(35 \%)$ & $63(41 \%)$ & \\
\hline Stage 2 & $201(57 \%)$ & $118(60 \%)$ & $83(54 \%)$ & \\
\hline Stage 3 & $17(5 \%)$ & $10(5 \%)$ & $7(4.5 \%)$ & $0.7^{*}$ \\
\hline \multicolumn{5}{|l|}{ Pathological stage } \\
\hline \multicolumn{5}{|l|}{ Patients with NAC } \\
\hline $\mathrm{pCR}$ & 16 & $10(18.2 \%)$ & $6(22 \%)$ & \\
\hline Stage 1 & 19 & $15(27.8 \%)$ & $4(15.4 \%)$ & \\
\hline Stage 2 & 32 & $21(38.9 \%)$ & $11(42.3 \%)$ & $0.79 *$ \\
\hline Stage 3 & 11 & $7(13 \%)$ & $4(15.4 \%)$ & \\
\hline
\end{tabular}


Table 1. Continued

\begin{tabular}{|c|c|c|c|c|}
\hline Characteristics & Total & Control group & Study group & p-value \\
\hline \multicolumn{5}{|l|}{ Patients without NAC } \\
\hline Stage 1 & 109 & $58(42.6 \%)$ & $51(46.4 \%)$ & \multirow{3}{*}{$0.32 *$} \\
\hline Stage 2 & 115 & $65(47.8 \%)$ & $50(45.5 \%)$ & \\
\hline Stage 3 & 20 & $13(9.6 \%)$ & $7(6.4 \%)$ & \\
\hline \multicolumn{5}{|c|}{ De novo Stage IV breast cancer } \\
\hline No & 355 (93\%) & $198(96.1 \%)$ & $157(89.2 \%)$ & \multirow{2}{*}{$0.009 *$} \\
\hline Yes & $27(7 \%)$ & $8(4 \%)$ & $19(10.8 \%)$ & \\
\hline \multicolumn{5}{|l|}{ NAC } \\
\hline Yes & $119(31.2 \%)$ & $66(32 \%)$ & $53(30 \%)$ & \multirow{2}{*}{$0.68^{*}$} \\
\hline No & $263(68.8 \%)$ & $140(68 \%)$ & $123(70 \%)$ & \\
\hline \multicolumn{5}{|l|}{ Surgical treatment } \\
\hline Mastectomy & $101(29 \%)$ & $56(29 \%)$ & 45 (29.4\%) & \multirow{2}{*}{$0.88^{*}$} \\
\hline Breast-conserving surgery & $247(71 \%)$ & $139(71 \%)$ & $108(70.6 \%)$ & \\
\hline \multicolumn{5}{|c|}{ Reconstruction with prosthesis } \\
\hline No & $49(48.5 \%)$ & $25(44 \%)$ & $24(54.5 \%)$ & \multirow{2}{*}{$0.32 *$} \\
\hline Yes & $51(51 \%)$ & $31(55.4 \%)$ & $20(45.5 \%)$ & \\
\hline \multicolumn{5}{|l|}{ Molecular subtype } \\
\hline Lum A & $125(33 \%)$ & $72(35 \%)$ & $53(30.6 \%)$ & \multirow{4}{*}{$0.29 *$} \\
\hline Lum B & $168(44.4 \%)$ & $91(44.4 \%)$ & 77 (44.5\%) & \\
\hline Her2 + & $32(8.5 \%)$ & $19(9.3 \%)$ & $13(7.5 \%)$ & \\
\hline TNBC & $53(14 \%)$ & $23(11.2 \%)$ & $30(17.3 \%)$ & \\
\hline \multicolumn{5}{|l|}{ Local recurrence } \\
\hline Yes & $15(3.9 \%)$ & $7(3.4 \%)$ & $8(4.5 \%)$ & \multirow{2}{*}{$0.56^{*}$} \\
\hline No & 367 (96.3\%) & 199 (96.6\%) & $168(95.5 \%)$ & \\
\hline
\end{tabular}

"Mann-Whitney U test, *Chi-square test.

NAC: Neoadjuvant chemotherapy, PRDT: Patient-related delay time, SDRT: System-related delay time, LVI: Lymphovascular invasion, USG: Ultrasonography, PCR: Pathologic complete response, MRI: Magnetic resonance imaging, CT: Computed tomography, PET: Positron emission tomography, TNBC: Triplenegative breast cancer

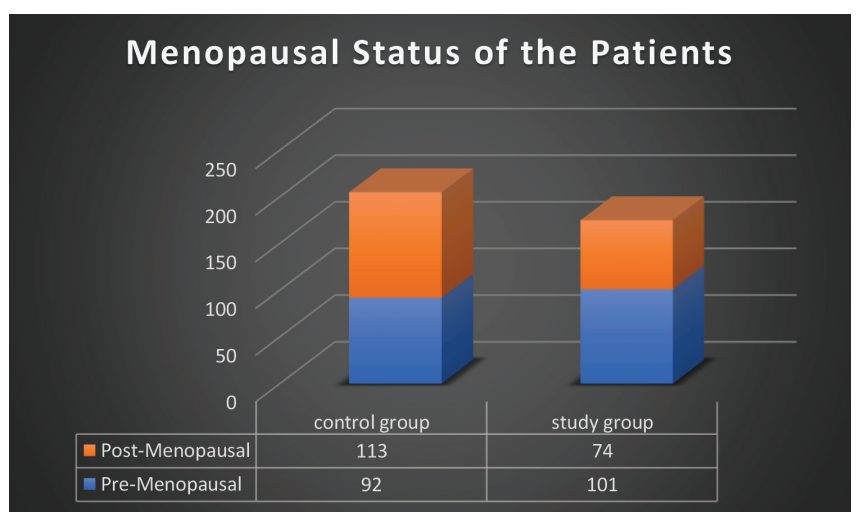

Figure 1. Menopausal status between the two groups

There was no difference between early and locally advanced breast cancer between the two groups (Figures 3, 4a and 4b), but there was more de novo stage IV breast cancer in the SG $(10.8 \%$ vs. $4 \%, \mathrm{p}=$

0.009) (Figure 5).

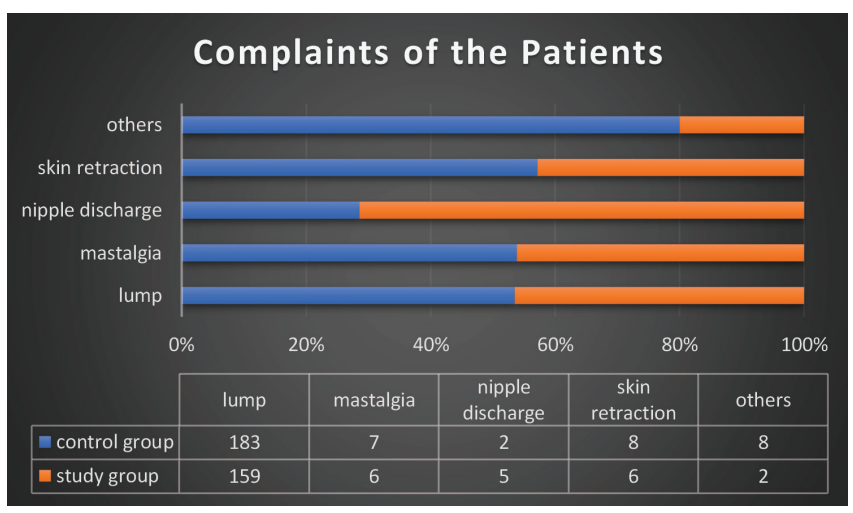

Figure 2. Complaints of patients during admission

There was a larger tumor size and more metastatic lymph nodes after NAC in the SG, but the differences were not significant. Clinical and pathologic stages, LVI (lymphovascular invasion), histologic grade, molecular subtypes, neo-adjuvant chemotherapy, and type of surgical 


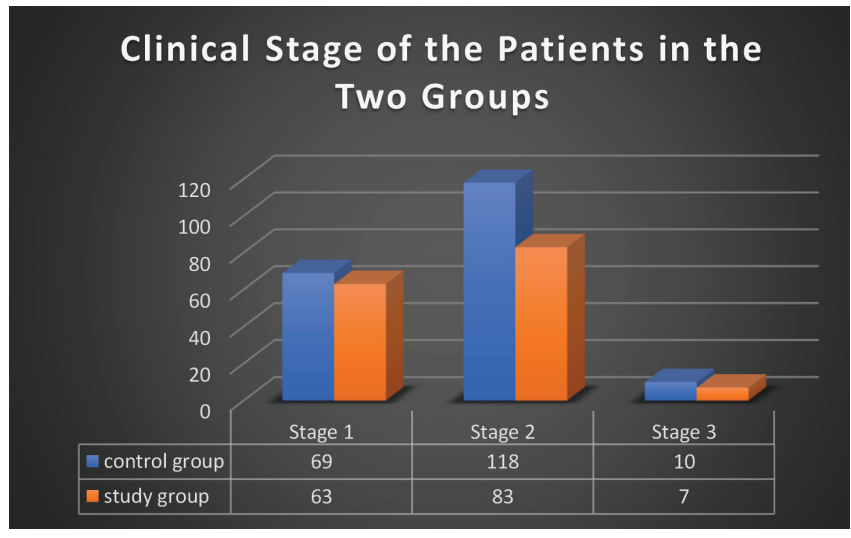

Figure 3. Clinical Stages of Patients
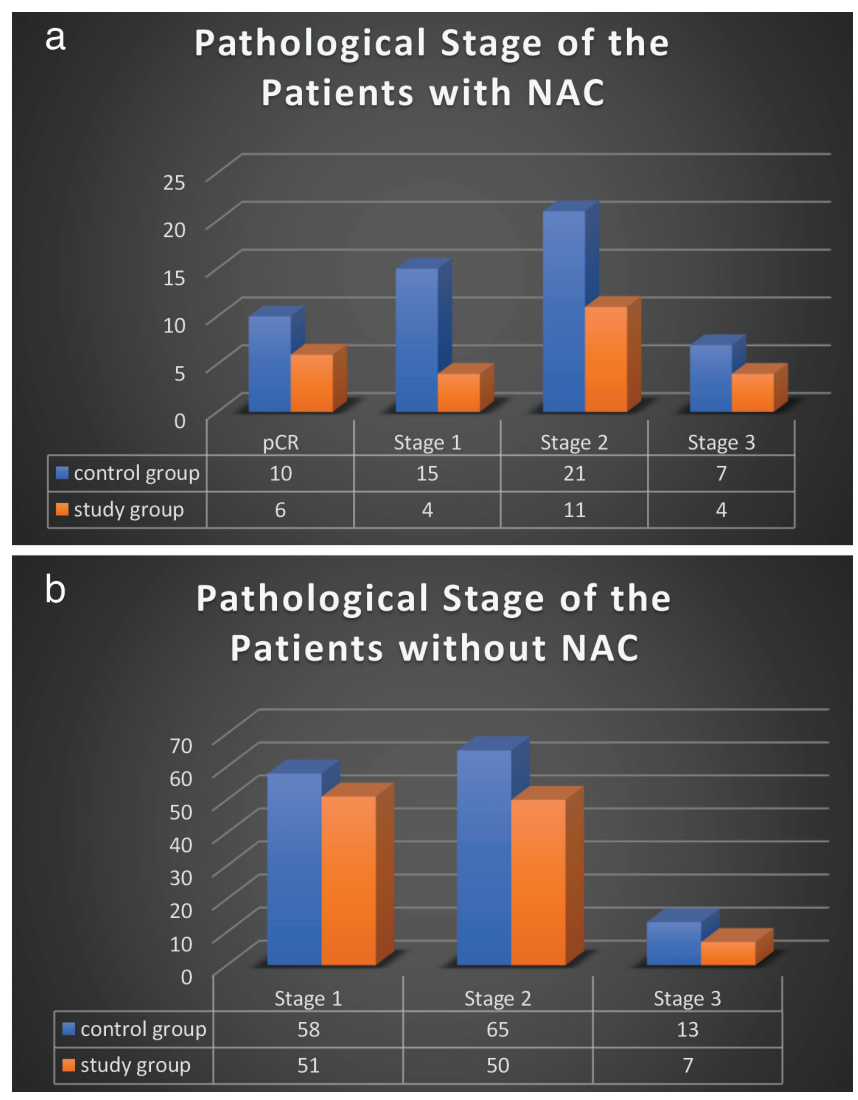

Figure 4. a) Pathologic Stages of Patients with NAC. b) Pathologic Stages of Patients without NAC

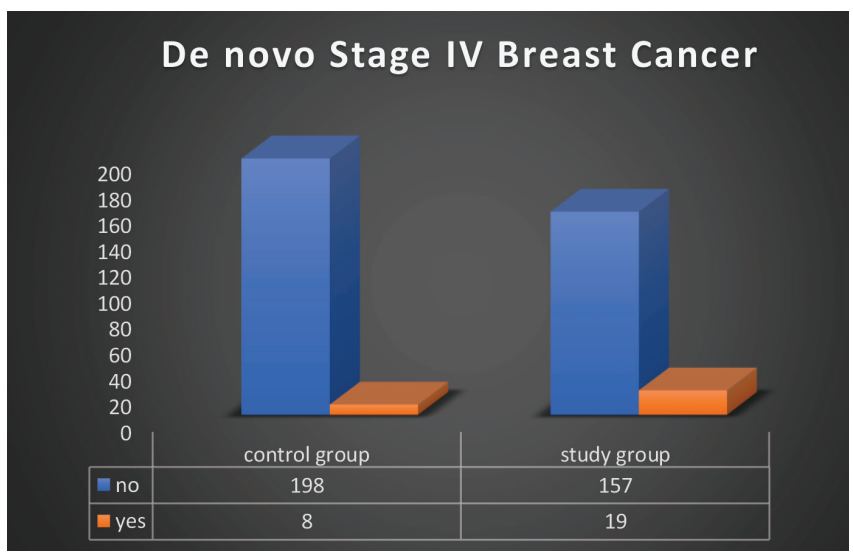

Figure 5. De novo Stage IV breast cancer therapy were similar between the two groups (Table 1). The staging was made mostly mammography and breast ultrasound. Almost half of the patients underwent breast magnetic resonance imaging (MRI) (Table 1).

\section{Discussion and Conclusion}

The number of urgent and elective surgical procedures and patient admissions to hospitals during the COVID-19 outbreak has decreased significantly compared with the pre-COVID-19 period. For example, Filipe et al. (7) found an overall decrease in the number of breast cancer patients undergoing surgery. Also, Dauti Işıklar et al. (8) detected a decline in the number of patients who consulted at their oncology clinic. Similarly, compared to last year, we observed an almost $15 \%$ reduction in the number of patients admitted to our center during the COVID-19 pandemic.

Immediate implant-based breast reconstruction is the treatment of choice after mastectomy. However, due to using the healthcare system more efficiently during the COVID-19 pandemic, many authors suggested keeping breast cancer surgical treatment simple and deferring reconstructive procedures (9). We observed a non-significant reduction in reconstructive surgical procedures in the COVID-19 period in our center. Mastectomy rates remained similar with the pre-COVID-19 period. The molecular subtypes and the number of patients with early or locally advanced disease were not significantly different between the two groups in our study. This may explain the lack of difference between patients who underwent neoadjuvant chemotherapy in both groups and the similarity of mastectomy rates.

Although patient age was not different between the two groups, the number of pre-menopausal women was significantly increased in the study group. This could result from the easing of lockdown only for women under 65 years in Turkey. A higher number of pre-menopausal women in SG may be a reason for more de novo metastases.

Several studies reported increased morbidity and mortality related to breast cancer diagnosis and treatment delays. These delays are related to patients and the healthcare system (10-12). In their study, Vanni et al. (13) concluded that the surgical refusal rate increased during the pandemic. COVID-19 related anxiety and fear of infection can be reasonable reasons that prevent patients from being admitted to the hospital. Accordingly, we found that the PRDT was significantly longer in the SG.

Delays in breast cancer diagnosis during the COVID-19 may affect oncological outcomes. Maringe et al. (14) calculated an estimated $8 \%-10 \%$ increase in deaths due to breast cancer after diagnosis. Vanni et al. (15) compared breast cancer patients operated on in COVID-19 period and before. Their study showed significantly more lymph node metastasis and advanced histological grade in patients operated in the COVID-19 period. However, there was no difference in tumor size and molecular subtypes. The proportion of metastatic disease was similar. Eijkelboom et al. (16) detected an increase in metastatic disease in April 2020 compared to the same period of the previous year. In our study, there was no significant difference between the two groups regarding tumor size, metastatic lymph nodes, histologic grade, LVI, clinical and pathologic stage. However, there was a significant increase in de novo metastatic disease in the study group. Shen et al. (17), found that ER, PR, and Her-2 status, high tumor grade, and race were significantly associated with an increased risk of de novo metastasis. More de novo metastatic disease might be explained by longer PRDT, 
more TNBC, and slightly higher-grade patients in SG, although nonsignificant. Also, there may be other factors rather than PRDT to explain the higher incidence of de novo stage IV breast cancer in SG. In 2012, a study from the United States found that median delay time was almost four weeks (29 days) in 72,586 women diagnosed with invasive breast cancers who had not received neoadjuvant treatment (18). In a multinational study, delay time was 11.5 weeks in Poland, 15.8 weeks in Bulgaria, and 25.5 weeks in Romania (12). Ozmen et al. (6) found that total, patient, and system-related delay times were $13.8,4.8$, and 10.5 weeks in breast cancer patients in Turkey. In the current study, PRDT during the COVID-19 pandemic was ten weeks (mean 2.55 \pm 2.1 months), and it was two times longer than PRDT in our previous study.

In conclusion, The COVID-19 pandemic has reduced patients' admission to our clinic, significantly increased patient-related treatment delay, and PRDT may cause the high frequency of de novo stage IV breast cancer in the COVID-19 pandemic.

Ethics Committee Approval: This study was approved by Demiroğlu Science University Clinical Researches Ethics Committee (date and decision no: 16.11.2021/2021-23-01).

Informed Consent: It was obtained.

Peer-review: Externally and internally peer-reviewed.

\section{Authorship Contributions}

Surgical and/or Medical Practices: S.İ., V.Ö.; Concept: S.İ., V.Ö.; Design: S.I.., V.Ö.; Data Collection and/or Processing: S.İ., V.Ö.; Analysis and/or Interpretation: S.İ., V.Ö.; Literature Search: S.İ., V.Ö.; Writing: S.İ., V.Ö.

Conflict of Interest: No conflict of interest declared by the authors.

Financial Disclosure: The authors declare that this study received no financial disclosure.

\section{References}

1. World Health Organization. Archived: WHO Timeline - COVID-19. Available at: https://www.who.int/news/item/27-04-2020-who-timeline--covid-19 [Crossref]

2. Sağlık Bakanlığı. Bakan Koca, Türkiye'nin Kovid-19'la 1 Yıllık Mücadele Sürecini Değerlendirdi. Available at: https://www.saglik.gov. $\operatorname{tr} / \mathrm{TR}, 80604 /$ bakan-koca-turkiyenin-kovid-19la-1-yillik-mucadelesurecini-degerlendirdi.html [Crossref]

3. COVIDSurg Collaborative. Global guidance for surgical care during the COVID-19 pandemic. Br J Surg 2020;1 07: 1097-1103. (PMID: 32293715) [Crossref]

4. COVIDSurg Collaborative. Elective surgery cancellations due to the COVID-19 pandemic: global predictive modelling to inform surgical recovery plans. Br J Surg. 2020; 107: 1440-1449. (PMID: 32395848) [Crossref]

5. Ponkilainen V, Kuitunen I, Hevonkorpi TP, Paloneva J, Reito A, Launonen AP, Mattila VM. The effect of nationwide lockdown and societal restrictions due to COVID-19 on emergency and urgent surgeries. Br J Surg 2020; 107: e405-e406. (PMID: 32770538) [Crossref]

6. Ozmen V, Boylu S, Ok E, Canturk NZ, Celik V, Kapkac M, et al. Factors affecting breast cancer treatment delay in Turkey: a study from Turkish Federation of Breast Diseases Societies. Eur J Public Health 2015; 25: 9-14 (PMID: 25096257) [Crossref]

7. Filipe MD, van Deukeren D, Kip M, Doeksen A, Pronk A, Verheijen PM, Heikens JT, et al. Effect of the COVID-19 Pandemic on Surgical Breast Cancer Care in the Netherlands: A Multicenter Retrospective Cohort Study. Clin Breast Cancer 2020; 20: 454-461. (PMID: 32888855) [Crossref]

8. Dauti Işıılar A, Deniz C, Soyder A, Güldoğan N, Yılmaz E, Başaran G. How Do Breast Cancer Patients Present Following COVID-19 Early Peak in a Breast Cancer Center in Turkey? Eur J Breast Health 2021; 17: 253 257. (PMID: 34263153) [Crossref]

9. Vidya R, Rubio IT, Paulinelli RR, Rancati A, Kolacinska-Voytkuv A, Salgarello M, et al. Should breast reconstruction and breast oncoplastic procedures be performed during the coronavirus pandemic? Ecancermedicalscience 2020; 14: 1041. (PMID: 32565894) [Crossref]

10. Smith EC, Ziogas A, Anton-Culver H. Delay in surgical treatment and survival after breast cancer diagnosis in young women by race/ethnicity. JAMA Surg 2013; 148: 516-523. (PMID: 23615681) [Crossref]

11. Hansen RP, Vedsted P, Sokolowski I, Søndergaard J, Olesen F. General practitioner characteristics and delay in cancer diagnosis. a populationbased cohort study. BMC Fam Pract 2011; 12: 100. (PMID: 21943310) [Crossref]

12. Jassem J, Ozmen V, Bacanu F, Drobniene M, Eglitis J, Lakshmaiah KC, et al. Delays in diagnosis and treatment of breast cancer: a multinational analysis. Eur J Public Health 2014; 24: 761-767. (PMID: 24029456) [Crossref]

13. Vanni G, Materazzo M, Pellicciaro M, Ingallinella S, Rho M, Santori F, et al. Breast cancer and COVID-19: the effect of fear on patients' decisionmaking process. In Vivo 2020; 34 (3 Suppl): 1651-1659. (PMID: 32503825) [Crossref]

14. Maringe C, Spicer J, Morris M, Purushotham A, Nolte E, Sullivan R, et al. The impact of the COVID-19 pandemic on cancer deaths due to delays in diagnosis in England, UK: a national, population-based, modelling study. Lancet Oncol. 2020; 21: 1023-1034. (PMID: 32702310) [Crossref]

15. Vanni G, Tazzioli G, Pellicciaro M, Materazzo M, Paolo O, Cattadori F, et al. Delay in breast cancer treatments during the first COVID-19 lockdown. A multicentric analysis of 432 patients. Anticancer Res 2020; 40: 7119-7125. (PMID: 33288611) [Crossref]

16. Eijkelboom AH, de Munck L, Vrancken Peeters MTFD, Broeders MJM, Strobbe LJA, Bos MEMM, et al; NABON COVID-19 consortium and the COVID and cancer-NL consortium. Impact of the COVID-19 pandemic on diagnosis, stage, and initial treatment of breast cancer in the Netherlands: a population-based study. J Hematol Oncol 2021; 14. doi: 10.1186/s13045-021-01073-7. (PMID: 33865430) [Crossref]

17. Shen T, Siegal GP, Wei S. Clinicopathologic factors associated with de novo metastatic breast cancer. Pathol Res Pract 2016; 212: 1167-1173. (PMID: 27692496) [Crossref]

18. Bleicher RJ, Ruth K, Sigurdson ER, Ross E, Wong YN, Patel SA, et al. Preoperative delays in the US Medicare population with breast cancer. J Clin Oncol 2012; 30: 4485-4492. (PMID: 23169513) [Crossref] 